\title{
A NEW PICTURE OF SWEDISH EARNINGS INEQUALITY: PERSISTENT AND TRANSITORY COMPONENTS, 1960-1990
}

\author{
By Magnus Gustavsson* \\ Uppsala University
}

\begin{abstract}
Using a large individual longitudinal database, I decompose the cross-sectional variance of male annual earnings in Sweden between 1960 and 1990 into persistent and transitory components. The persistent variance displays a downward trend during the whole sample period, but with the rate of decline more rapid up until the early 1980s than afterwards. The transitory variance has increased from 1960 until the early 1970s, decreased slightly until the late 1970s, and then risen again during the second half of the 1980s. An important lesson from these results concern the interpretation of the rise in cross-sectional inequality observed after the 1983 breakdown of centralized bargaining in Sweden. While it has often been presumed that this growth reflected increased returns to skills, this study shows that it was in fact due to increased transitory earnings fluctuations.
\end{abstract}

\section{INTRODUCTION}

Sweden has an interesting history of marked changes in earnings inequality. There was precipitous pay compression from the late 1960s through the 1970s, followed by a trend increase during the 1980s. While several countries also experienced pay compression during the 1970s, few, if any, match the magnitude and rapidness of that in Sweden (e.g. Freeman and Katz, 1995).

The evolution of Swedish inequality has been the focus of several studies since it constitutes a unique basis for investigating how changes in the functioning of the labor market co-vary with changes in pay inequality. In particular, several sharp institutional changes have occurred in Sweden between 1960 and 1990 which seem to have affected wage dispersion (see Hibbs, 1990; Edin and Holmlund, 1995; Edin and Topel, 1997; Hibbs and Locking, 2000). One notable turning point was the 1983 breakdown of centralized wage bargaining, present since the mid 1950s, and the subsequent shift to a system of industry-wide bargaining.

Another important and interesting period in the Swedish labor market was the powerful implementation of the "solidarity wage policy" pursued by the major blue-collar union, Landsorganisationen (LO), whose heyday coincides with the great wage compression beginning in the late 1960s. The policy was gradually brought into practice during the 1950s and had as its aim "equal pay for equal work," meaning that wage differentials were to be independent of differences in profitability between regions, industries or firms. However, from the late 1960s to

Note: I have received useful comments and suggestions from Per-Anders Edin, Meredith Beechey, Anders Björklund, Patrik Hesselius, Bertil Holmlund, Stephen Jenkins, Markus Jäntti, the editor Stephan Klasen, two anonymous referees, and participants at seminars at Uppsala University, Stockholm University (SOFI) and IZA Summer School. Financial support from the Jan Wallander and Tom Hedelius Foundation is gratefully acknowledged.

*Correspondence to: Magnus Gustavsson, Department of Economics, Uppsala University, Box 513, SE-751 20 Uppsala, Sweden (Magnus.Gustavsson@nek.uu.se). by Blackwell Publishing, 9600 Garsington Road, Oxford OX4 2DQ, UK and 350 Main St, Malden, MA, 02148, USA. 
the breakdown of centralized bargaining in 1983, the policy also successfully invoked equalization of wages between all kinds of jobs by giving especially large pay increases to the lowest paid workers.

Traditionally, most studies of Swedish earnings inequality, as well as studies for other countries, have focused on changes in measures of cross-sectional earnings inequality, focusing on such measures as the cross-sectional variance. However, several U.S. studies (Gottschalk and Moffitt, 1994; Haider, 2001; Moffitt and Gottschalk, 2002) highlight that such measures neglect an important dimension of changes in earnings inequality - the division into persistent and transitory earnings components. In particular, they show that the rapid increase in U.S. earnings inequality during the 1980 s was due not only to increased dispersion of persistent earnings, but also to increased individual year-to-year earnings fluctuations.

As the U.S. research suggests, to understand the sources of inequality change it is crucial to know whether changes in cross-sectional inequality are the result of changes in the dispersion of persistent or transitory earnings. Increased dispersion in persistent earnings increases both short- and long-term inequality. Increased dispersion in transitory earnings, on the other hand, only increases short-term inequality.

No previous study has decomposed changes in Swedish cross-sectional inequality into its persistent and transitory components for the period 1960-90. In fact, very little is known at all about persistent or transitory earnings inequality in Sweden prior to 1968. Previous studies examining either earnings inequality or earnings dynamics before 1968 have either used data for a specific group within the labor market for which data has been available, or have used small samples and a broader income measure which also has included capital income and realization of capital. ${ }^{1}$

In this paper I fill part of the knowledge gap by offering a new picture of Swedish earnings inequality using previously unexploited longitudinal earnings data for 1960-67 together with longitudinal earnings data for 1968-90, resulting in an earnings panel spanning 31 years. Based on these data, I am able to estimate how the persistent and transitory components of annual earnings inequality have evolved over the three decades spanning 1960 to 1990. To put the findings for Sweden into perspective, the obtained results are also contrasted to what is known for other countries during the same period.

Besides increasing our knowledge about Swedish earnings inequality per se, this paper has four main contributions. First, though previous studies have shown that implementations of egalitarian wage policies, such as the solidarity wage policy, coincide with reduced dispersion in cross-sectional earnings (e.g. Katz and Autor, 1999), little is known about the connection to longer-run measures of inequality. This study adds new knowledge to this field by being the first to provide a truly long-run picture - 31 years - of persistent and transitory inequality for a country with a history of pronounced egalitarian goals. In particular, by being able

${ }^{1}$ Previous Swedish studies that use pre-1968 data include Spånt (1979), Hibbs (1990), Björklund (1993) and Edin and Holmlund (1995). Important studies on income dynamics and inequality in Sweden also include Gustafsson (1994) and Palme (1995). 
to describe earnings dynamics in Sweden before 1968, and thus inequality trends prior to the heyday of the solidarity wage policy, more can be learned about how this policy co-varied with inequality, and in the extension, how institutions generally affect inequality and earnings instability. Second, by obtaining results for Sweden, I am able to provide a cross-national overview of changes in persistent and transitory inequality for a sample of countries with markedly different institutional settings in the labor market: Canada, Italy, Sweden, the U.K., and the U.S. Of these, Sweden and Italy have more unionized and regulated labor markets, whereas the U.S. is at the other end of the spectrum (Cahuc and Zylberberg, 2004). Third, the paper utilizes richer longitudinal data than any previous study, both in terms of the number of years and the sample size. I am therefore able to estimate a very detailed picture of how persistent and transitory shocks to earnings vary over the life-cycle. Fourth, for studies of the covariance structure of earnings, the paper proposes a method to splice two data sets.

Previewing the main results found in this paper, the persistent variance displays a downward trend during the whole sample period but with the rate of decline more rapid up until the early 1980s than afterwards. The transitory variance has increased from 1960 until the early 1970s, decreased slightly until the late 1970s, and then risen again during the second half of the 1980s. An important lesson from these results concerns the interpretation of the rise in cross-sectional inequality observed after the 1983 breakdown of centralized bargaining. While it has often been presumed that this growth reflected increased dispersion in persistent earnings, this study shows that it was in fact due to increased dispersion in transitory earnings. The results also reveal a trend decrease in persistent inequality already before 1968 - the starting year in previous studies and the period when the strongly egalitarian version of the solidarity wage policy was brought into practice. This could mean that the solidarity wage policy had a smaller role in the compression of wages in Sweden than is commonly believed.

The remainder of the paper is organized as follows. Section 2 describes the parametric model of persistent and transitory inequality used in the analysis. Section 3 documents the data sources and the data preparation. Section 4 contains the results for the parametric model outlined in Section 2. To put the changes in Swedish inequality in perspective, Section 5 compares the findings for Sweden to what is known about developments in other countries. The paper ends with concluding remarks.

\section{Parametric Models of Earnings Dynamics}

This section describes the parametric model that I use to decompose changes in cross-sectional inequality into persistent (long-run) and transitory (instability) components. To provide intuition behind this model, I first describe a more basic model of earnings dynamics.

Let $Y_{i b t}$ denote the log of earnings in year $t$ of the $i$-th individual born in year b. Then

$$
Y_{i b t}=\mu_{b t}+y_{i b t}
$$


expresses $Y_{i b t}$ as the cohort specific mean $\mu_{b t}$ in year $t$ plus an individual specific deviation $y_{i b t}$ from that mean. A stripped down model for $y_{i b t}$ is

$$
y_{i b t}=p_{t} u_{i b}+\lambda_{t} \varepsilon_{i b t} .
$$

In equation (2), the variable $u_{i b}$ and its year-specific factor loading, $p_{t}$, capture persistent, or permanent, relative earnings. The variable $\varepsilon_{i b t}$ and its factor loading, $\lambda_{t}$, capture stochastic transitory deviations from persistent earnings. The transitory component is serially uncorrelated with mean zero, and $\mu_{i b}$ and $\varepsilon_{i b t}$ are uncorrelated with variances $\sigma_{u}^{2}$ and $\sigma_{\varepsilon}^{2}$ respectively. With these assumptions, the variance of log earnings is

$$
\operatorname{Var}\left(y_{i b t}\right)=p_{t}^{2} \sigma_{u}^{2}+\lambda_{t}^{2} \sigma_{\varepsilon}^{2} .
$$

Equation(3) shows that an increase in either factor loading generates increased cross-sectional earnings dispersion. The character of the change depends crucially, however, on which of the factor loadings changes. A persistent rise in $p_{t}$ increases long-run inequality as the relative labor market advantage of workers with chronically high earnings is enhanced. An increase in $\lambda_{t}$ without any change in $p_{t}$ generates increased cross-sectional earnings dispersion by raising year-to-year earnings instability but with no change in long-run inequality.

Although the model in equation (2) is intuitive, previous studies have shown that it is likely to be too restrictive to adequately capture changes in persistent and transitory inequality. A more realistic model of earnings dynamics should also allow for individual specific changes in persistent earnings, serial correlation in transitory earnings, age heteroscedasticity in transitory shocks to earnings, and potentially also cohort differences in persistent and transitory earnings; see Baker and Solon (2003) and the references therein. To incorporate these features, I use the following generalization of equation (2):

$$
y_{i b t}=p_{t} q_{b} u_{i a}+\varepsilon_{i b t},
$$

where

$$
\begin{gathered}
u_{i a}=u_{i, a-1}+r_{i a}, \\
\varepsilon_{i b t}=\rho_{t} \varepsilon_{i b, t-1}+\delta_{t} \lambda_{t-1} v_{i b, t-1}+\lambda_{t} v_{i b t},
\end{gathered}
$$

and

$$
\operatorname{Var}\left(v_{i b t}\right)=\gamma_{0}+\gamma_{1} a+\gamma_{2} a^{2}
$$

where $a=t-b-27$, i.e. years since age 27 (by definition the lowest age in my sample).

Beginning with the persistent component, $q_{b}$ in equation (4) is a cohortspecific parameter that allows the dispersion of persistent earnings to differ between cohorts. Equations (4) and (5) describe the persistent component as a 
random walk in age where $r_{i, a} \sim \operatorname{iid}\left(0, \sigma_{r, \mathrm{a}}^{2}\right)$ is the innovation at each age. ${ }^{2}$ In previous research it is common to force the innovation variance $\sigma_{r, \mathrm{a}}^{2}$ to be the same over the whole life cycle but because of my rich data, I do not have to impose this restriction. Rather, the innovation variance is only restricted to be the same for two ages at a time, i.e. individuals aged 28 and 29 have one variance, those aged 29 and 30 have another variance, and so forth. I also estimate the variance of an initial persistent shock, denoted $\sigma_{u}^{2}$. This specification of the persistent component recognizes that younger individuals are more likely to be engaged in job shopping and have no job securing tenure and therefore are likely to have larger persistent shocks to earnings.

For the transitory component, equation (6) models deviations from persistent earnings as a first order autoregressive moving average process, $\operatorname{ARMA}(1,1)$, with year-specific factor loadings, $\lambda_{t}$, on the innovation $v_{i b t}{ }^{3}$ This specification implies that luck follows luck in the sense that a positive transitory shock dies out gradually. Equation (6) also allows the ARMA-parameters, $\rho_{t}$ and $\delta_{t}$, to vary over time. More specifically, they are allowed to differ between, but not within, the periods 1960-67 and 1968-90; the reasons for this are discussed in the data section.

Equation (6) shows that transitory earnings for an individual in cohort $b$ in year $t$ is a function of transitory earnings in year $t-1$, which in turn is a function of transitory earnings in year $t-2$, and so on. This auto-regressive process induces a recursive structure in the moments. If one traces the recursion back to a cohort's first sample year, this raises the question of what the value of the transitory variance is in that year. As pointed out by MaCurdy (1982), a time series approach to this problem is problematic since the assumption of infinite history is untenable. I therefore follow the approach of Baker and Solon (2003) and estimate separate initial transitory variances for each cohort. This recognizes that earnings instability varies across cohorts because they are at different stages of the life cycle and have lived through different times. Consistent with separate initial variances, equation (7) allows the variance of $v_{i b t}$ to be a quadratic function of age.

Although the model in equations (4)-(7) is more complex than that in equation (2), the intuition from the simpler model still holds. An increase in the persistent variance raises long-run inequality. An increase in the transitory variance leads to more scrambling of workers' order in the annual earnings distribution, and the scrambling gets redone every year.

The parameters of the model in equations (4)-(7) are estimated by applying the minimum distance estimator of Chamberlain (1984). Basically, the implied variances and auto-covariances of the model in equations (4)-(7) are fitted to the corresponding empirical moments in the data by non-linear least squares. Appendix A contains a description of the estimation procedure.

I have also experimented with other specifications of earnings dynamics than that in equations (4)-(7). In particular, another potential specification of the persistent component is the so-called "random growth model." The basic version of this model is $\alpha_{i b}+\beta_{i b} a$, where $\alpha_{i b}$ and $\beta_{i b}$ are individual specific parameters. With

${ }^{2} \mathrm{~A}$ random walk specification is also used, among others, in Dickens (2000) and Moffitt and Gottschalk (2002).

${ }^{3}$ Note that this refers to the Box-Jenkins definition of a moving average; see, e.g. Hamilton (1994) for details. 
this specification, each individual has a predetermined age-earnings profile around which there are transitory shocks. The variance for the random growth model is $\sigma_{\alpha}^{2}+2 \sigma_{\alpha \beta} a+\sigma_{\beta}^{2} a^{2}$, where $\sigma_{\alpha \beta}$ is the covariance between $\alpha_{i b}$ and $\beta_{i b}$, which may be negative, and $\sigma_{\alpha}^{2}$ and $\sigma_{\beta}^{2}$ are the variances of $\alpha_{i b}$ and $\beta_{i b}$, respectively. However, trials with this model always resulted in negative estimates of the variance $\sigma_{\beta}^{2}$, plus positive estimates of $\sigma_{\alpha}^{2}$ and $\sigma_{\alpha \beta}{ }^{4}$ This indicates that persistent inequality rises with age at a diminishing rate - a pattern that the random growth model does not encompass. ${ }^{5}$ This pattern is also confirmed by the final results, which are discussed in Section 4.

Baker and Solon (2003) for Canada 1976-92, and Ramos (2003) for the U.K. 1991-99 manage to incorporate both a random growth and a random walk term in their models of persistent earnings. I am not able to do this, as the estimate of $\sigma_{\beta}^{2}$ still is negative with this strategy. The data that I use are richer than the data used by Baker and Solon (2003) and Ramos (2003), both in terms of the number of years and the cross-sectional sample size (see Section 3 below). Hence, their ability to incorporate both specifications could be due to a different covariance structure of earnings in the U.K. and Canada than in Sweden. However, Dickens (2000) studies the covariance structure of earnings in the U.K. between 1975 and 1995 and also finds that the persistent component is best modeled as a random walk with agespecific shocks, resulting in a model of the persistent component that is very similar to the one employed in this paper. The differences between Ramos (2003) and Dickens (2000) in what model best fits the data is thus likely to be due to differences in panel length, which indicates that the same type of model best describes persistent earnings in Sweden and the U.K. as long as long enough panels are used.

For the transitory component, I initially experimented with an $\operatorname{ARMA}(1,2)$ specification. This did, however, result in imprecise estimates, which indicates the inclusion of redundant parameters. Consequently, I instead use an $\operatorname{ARMA}(1,1)$ specification.

I have not applied Newey's (1985) specification test to any model as the previous literature on earnings dynamics show that this test always (at least in the studies that I am aware of) rejects the hypothesis that the right model is specified. The drawbacks with this test for assessing the goodness of fit of models of earnings dynamics are further discussed in Baker (1997) and Baker and Solon (2003). A general critic of tests such as that proposed in Newey (1985) is also found in Leamer (1983).

\section{DAta}

This section is divided into three sub-sections. The first describes the data source and the sample construction. The second contains an overview of annual

${ }^{4}$ These estimates are available on request.

${ }^{5}$ To see this, note that when the model is submitted to data, i.e. to the variances and the covariances of earnings, age variation in persistent inequality is captured by the following polynomial in age: $\beta_{1}+\beta_{2} a+\beta_{3} a^{2}$, where $\beta_{1}=\sigma_{\alpha}^{2}, \beta_{2}=2 \sigma_{\alpha \beta}$, and $\beta_{3}=\sigma_{\beta}^{2}$ are the parameters to be estimated. Hence when persistent inequality increases with age at a diminishing rate, one will obtain $\hat{\beta}_{1} \geq 0, \hat{\beta}_{2}>0$, and $\hat{\beta}_{3}<0$, and hence $\hat{\sigma}_{\beta}^{2}<0$. 
earnings dispersion in Sweden during 1960-90. Part of the earnings data for 1960-67 is top-coded; the last sub-section describes how I have adjusted these data.

\subsection{Data Source and Sample Construction}

The data come from the Swedish longitudinal database LINDA (Longitudinal Individual Data for Sweden), constructed to be cross-sectionally representative of the Swedish population each year from 1968 onwards (see Edin and Fredriksson, 2000). The dataset is large; it contains 3.35 percent of the Swedish population each year, amounting to around 300,000 individuals. All information is based on administrative registers, which confers several advantages compared to an analysis based on survey data. First, there is no outflow apart from death or migration, thus the data are free of the kind of sample attrition common in surveys. Second, the data are highly reliable; information from administrative registers is likely to be better than the recall of individuals.

Information on individual earnings is annually available for the LINDA samples from 1968 onwards in the Income Register, which is based on tax reports. For the 1960-67 period, I use the Pensionable Income Register. ${ }^{6}$ This register is available for the 1990 LINDA sample and contains information on annual labor earnings from 1960 onwards that form the basis for supplementary old-age pensions ("ATP-poäng"). ${ }^{7}$ For both 1960-67 and 1968-90, the measure of earnings used in the analysis contains earnings from all jobs, including self-employment, held by an individual during a year. ${ }^{8}$ However, during $1968-73$ it is not possible to separate pensions from labor earnings. ${ }^{9}$

As the purpose of the 1960-67 data is to inform on supplementary old-age pensions for the 1990 LINDA sample, it suffers from four shortcomings from the point of view of the current analysis. First, individuals working in the period 1960-67 must still be alive and living in Sweden in 1990 in order to be observed. This means that the earnings sample 1960-67 might not be random, as people with bad health probably are less likely to still be alive in 1990. Second, information on annual earnings is missing if an individual had any form of pension during a year,

\footnotetext{
${ }^{6}$ As taxable labor income forms the basis for pensionable income, the Pensionable Income Register contains information derived from the Income Register. Also, both registers are part of LINDA, which is constructed, kept and maintained by Statistics Sweden for the purpose of research.

${ }^{7}$ See Riksförsäkringsverket (1984) for detailed information on the calculation of earnings that form the basis for supplementary old-age pension.

${ }^{8}$ It is not obvious whether self-employed income should be included or not. Consistency with the U.S. studies is, however, one reason for including self-employment income. Also, in the 1960-67 data, it is not possible to observe whether earnings stem from self-employment or from regular employment, and this is an additional reason why I have included self-employed income during all sample years.

${ }^{9}$ It is further not possible to exclude parental leave benefits from 1974 onwards. This should, however, be of minor consequence since I only study men. In detail, the following variables from the Income Register have been used to construct earnings for 1968-90. During 1968-77, I added income from employment (A-inkomst av tjänst + sjöinkomst) and income from business (A-inkomst av jordbruk + A-inkomst av rörelse). From 1978 onwards, I have used the pre-calculated measure of labor earnings that is available in LINDA (arbetsinkomst). To obtain consistent earnings measures over time, I subtracted the sum of pensions (pension), unemployment compensation (dagpenning vid arbetslöshet $+K A S$ ), compensation during labor market training (utbildningsbidrag) from income from employment and business during 1974-77. From 1974 onwards, I also subtracted sickness benefits (sjukpenning av anställning + sjukpenning av annan förvärvskälla). See Edin and Fredriksson (2000) for further details on the income measures in LINDA.
} 
because these years did not qualify for supplementary old-age pension. Third, earnings have to be above a specific threshold to form the basis for supplementary old-age pension - the so-called "basic amount"; the basic amount was 4,200 SEK in 1960, which corresponds to 42,082 SEK in 2004 (5,400 USD or 4,500 EUR), and has since been adjusted annually for inflation. This data restriction means that, for a given year 1960-67, I can only observe annual earnings for those individuals who earned more than the basic amount. Lastly, part of the earnings data are top-coded because earnings above 7.5 times the basic amount did not form the basis for supplementary old-age pension. Because the ceiling is constant in real terms and real wages increased during the 1960s, the percentage of earnings that are topcoded increases over time. Despite these drawbacks with the 1960-67 data, they constitute a unique opportunity to gain insights into individual earnings dynamics in Sweden before 1968-something that no previous studies have been able to touch on.

The analysis in this paper is based on men born in Sweden aged 26-53. This age range should ensure that individuals are old enough to have completed their education and young enough not to be considered for early retirement. The upper age of 53 hence limits the effects of missing information on annual earnings in the 1960-67 data for individuals receiving pension during part of a year. It should also limit the potential non-representativeness of the 1960-67 data originating from the requirement of being alive in 1990 . The inability to exclude pensions from the earnings measure during 1968-73 should also be of minor consequence with this age-range. The restriction to males in the study is because the large changes in female labor force participation during the sample period would confound an analysis of female earnings. ${ }^{10}$

For the empirical analysis, I categorize individuals into two-year births cohorts and follow them through time. I include cohorts who are between the age 26 and 53 for at least 6 years between 1960 and 1990. ${ }^{11}$ The youngest two-year cohort is aged 26 and 27 in 1985 (born in 1958/59), the next youngest is 26 and 27 in 1983 (born in 1956/57), and so on down to the oldest cohort, aged 47 and 48 in 1960 (born in 1912/13). Cohorts can be present in the sample between 6 and 27 years, depending on their date of birth. This gives a total of 24 two-year birth cohorts. The first three columns of Table 1 list the cohorts included in the sample, the years that they are observed, and their age in the initial year. The second column of Table 2 contains for each year the resulting age intervals in the total, pooled sample.

In order to maximize the sample used and not to transfer the potential sample selection effects present in 1960-67 to later data, I include all earnings observations

\footnotetext{
${ }^{10}$ The results would be confounded because I estimate a model of earnings, not of entry and exit; appending a model of entry and exit is beyond the scope of this paper. The same argument applies to the exclusion of foreign-born men, as there has been substantial immigration into Sweden during the sample period.

${ }^{11}$ The LINDA database continues beyond 1990. These years are not included since there was a major tax reform in Sweden in 1991 which markedly changed the definition of earnings in LINDA, making the results hard to interpret (as the earnings variable in LINDA steams from tax-reports). There is also the issue of the deep economic crisis in Sweden during the 1990s, something that would both call for a different way of constructing the sample (see Gustavsson, 2007) and make it hard to compare the results before and after 1990.
} 
TABLE 1

COHORTS INCLUded IN THE SAMPLE

\begin{tabular}{lccc}
\hline \hline Birth Year & Years Observed & Age in Initial Year & Sample Size \\
\hline $1912 / 13$ & $1960-65$ & 48 & 1,650 \\
$1914 / 15$ & $1960-67$ & 46 & 1,789 \\
$1916 / 17$ & $1960-69$ & 44 & 3,078 \\
$1918 / 19$ & $1960-71$ & 42 & 3,134 \\
$1920 / 21$ & $1960-73$ & 40 & 3,465 \\
$1922 / 23$ & $1960-75$ & 38 & 3,219 \\
$1924 / 25$ & $1960-77$ & 36 & 3,063 \\
$1926 / 27$ & $1960-79$ & 34 & 2,804 \\
$1928 / 29$ & $1960-81$ & 32 & 2,840 \\
$1930 / 31$ & $1960-83$ & 30 & 2,722 \\
$1932 / 33$ & $1960-85$ & 28 & 2,623 \\
$1934 / 35$ & $1961-87$ & 26 & 2,683 \\
$1936 / 37$ & 26 & 2,698 \\
$1938 / 39$ & $1963-89$ & 26 & 3,057 \\
$1940 / 41$ & $1965-90$ & 26 & 3,094 \\
$1942 / 43$ & $1967-90$ & 26 & 3,889 \\
$1944 / 45$ & $1969-90$ & 26 & 4,428 \\
$1946 / 47$ & $1971-90$ & 26 & 4,220 \\
$1948 / 49$ & $1973-90$ & 26 & 3,979 \\
$1950 / 51$ & $1975-90$ & 26 & 3,554 \\
$1952 / 53$ & $1977-90$ & 26 & 3,594 \\
$1954 / 55$ & $1979-90$ & 26 & 3,509 \\
$1956 / 57$ & $1981-90$ & 26 & 3,428 \\
$1958 / 59$ & $1983-90$ & 26 & 3,406 \\
Total & $1985-90$ & & 76,079 \\
\hline
\end{tabular}

Note: Age is defined by the older of the birth cohorts in each two-year cohort.

larger than the basic amount for each individual over the period 1960-90, allowing individuals to re-enter the panel if they do exit. ${ }^{12,13}$ The restriction to earnings above the basic amount is to be able to get comparable estimates of earnings inequality for the 1960-67 and 1968-90 periods.

The end result of the sample construction is an unbalanced panel as some individuals die or migrate during the sample period and others do not have earnings above the basic amount during the whole sample period. The last column of Table 1 lists the resulting sample size for each two-year birth cohort. For the pooled sample, the third and fourth columns of Table 2 contain for each year the total sample size and the number of individuals excluded because they have earnings below the basic amount. The last column of Table 2 also reports the percentage of earnings that are top-coded in the 1960-67 data. In total, the 1960-90 panel consists of 76,079 men and 1,144,667 individual-year observations. This should be compared to the sample sizes of 3,115 and 2,988 individuals used in the equivalent U.S. studies by Haider (2001) and Moffitt and Gottschalk (2002), respectively.

\footnotetext{
sample.

${ }^{12}$ That is, for a given year, individuals with incomes below the basic amount are omitted from the

${ }^{13}$ Even though an unbalanced design is used, there will be a slight selection in the sample since men with a high degree of labor force attachment will be present for longer periods. This is a problem common to all studies in the literature.
} 
TABLE 2

Description of the Pooled Sample

\begin{tabular}{|c|c|c|c|c|}
\hline Year & Age & $\begin{array}{l}\text { \# Individuals } \\
\text { in the Sample }\end{array}$ & $\begin{array}{c}\text { \# Individuals Excluded due } \\
\text { to Earnings }<\text { Basic } \\
\text { Amount }\end{array}$ & $\begin{array}{l}\% \text { Top-Coded } \\
\text { in the Sample }\end{array}$ \\
\hline 1960 & $27-48$ & 23,585 & 2,069 & 4.64 \\
\hline 1961 & $26-49$ & 25,962 & 2,164 & 5.51 \\
\hline 1962 & $27-50$ & 25,960 & 2,166 & 6.44 \\
\hline 1963 & $26-51$ & 28,503 & 2,152 & 6.69 \\
\hline 1964 & $27-52$ & 28,650 & 2,005 & 8.74 \\
\hline 1965 & $26-53$ & 31,433 & 2,116 & 9.67 \\
\hline 1966 & $27-52$ & 29,776 & 2,039 & 11.32 \\
\hline 1967 & $26-53$ & 32,409 & 2,371 & 12.07 \\
\hline 1968 & $27-52$ & 34,326 & 4,272 & - \\
\hline 1969 & $26-53$ & 38,768 & 3,681 & - \\
\hline 1970 & $27-52$ & 36,771 & 2,467 & - \\
\hline 1971 & $26-53$ & 40,978 & 2,686 & - \\
\hline 1972 & $27-52$ & 37,879 & 2,625 & - \\
\hline 1973 & $26-53$ & 41,762 & 2,842 & - \\
\hline 1974 & $27-52$ & 38,322 & 2,689 & - \\
\hline 1975 & $26-53$ & 41,934 & 2,954 & - \\
\hline 1976 & $27-52$ & 38,974 & 2,611 & - \\
\hline 1977 & $26-53$ & 41,953 & 3,096 & - \\
\hline 1978 & $27-52$ & 39,164 & 2,794 & - \\
\hline 1979 & $26-53$ & 42,230 & 3,214 & - \\
\hline 1980 & $27-52$ & 39,796 & 2,812 & - \\
\hline 1981 & $26-53$ & 42,731 & 3,326 & - \\
\hline 1982 & $27-52$ & 39,887 & 3,324 & - \\
\hline 1983 & $26-53$ & 42,815 & 3,727 & - \\
\hline 1984 & $27-52$ & 40,427 & 3,423 & - \\
\hline 1985 & $26-53$ & 43,393 & 3,829 & - \\
\hline 1986 & $27-52$ & 41,089 & 3,547 & - \\
\hline 1987 & $28-53$ & 41,142 & 3,344 & - \\
\hline 1988 & $29-52$ & 38,873 & 3,036 & - \\
\hline 1989 & $30-53$ & 38,728 & 3,075 & - \\
\hline 1990 & $31-52$ & 36,447 & 3,014 & - \\
\hline
\end{tabular}

I have examined the extent to which individuals disappear from the sample over time for selected two-year birth cohorts and years (see Gustavsson, 2004, for details). The numbers for the cohort born in 1928/29 constitute a representative example. In this cohort, 2,309 individuals are present in 1960. Of these, 98 percent are present in 1965, and 93 percent are still present in 1980. Overall, the extent to which individuals disappear from my sample must be considered to be very low. For example, in the corresponding U.K. study by Dickens (2000) it is reported that around 50 percent in a given cohort are still present after 20 years. ${ }^{14}$

To be able to estimate the parameters of the model in equations (4)-(7), I take each cohort separately and, after adjusting the top-coded earnings in the period 1960-67 (described below), estimate the variances and auto-covariances of log annual earnings. Computing auto-covariance matrices for each cohort results in a total of 4,188 distinct variance and auto-covariance elements; these are the data to which the model in equations (4)-(7) is fitted.

\footnotetext{
${ }^{14}$ Other equivalent studies do not report these numbers.
} 


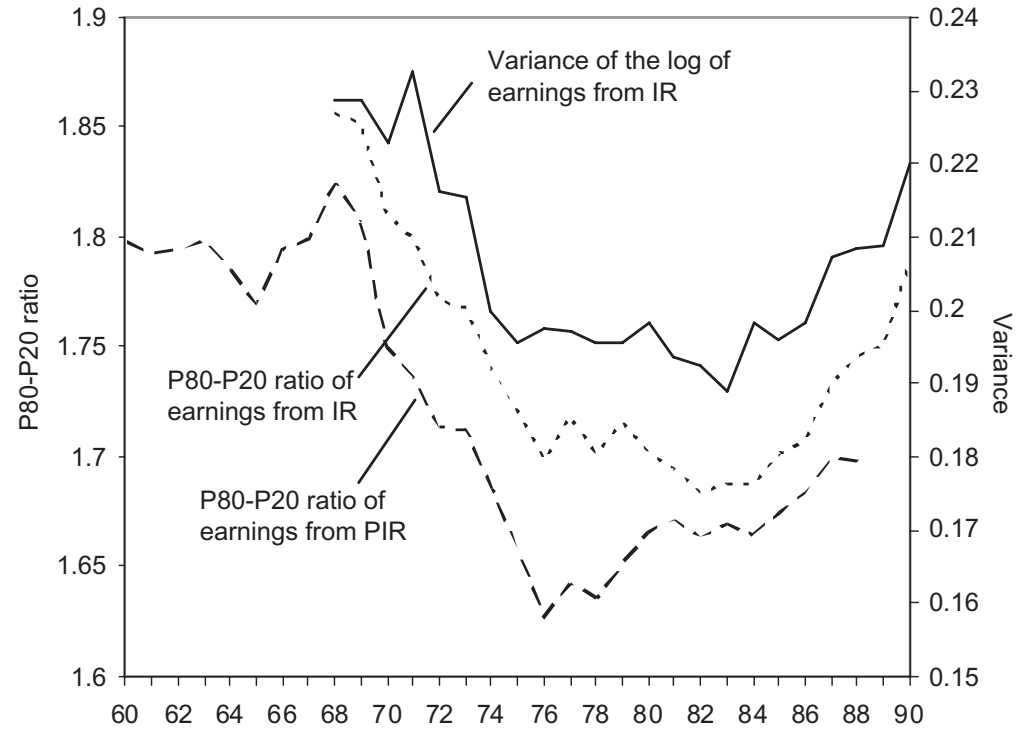

Figure 1. Annual Earnings Inequality in Sweden 1960-90

Note: Sample ages are used each year; see Table 1.

\subsection{Overview of Annual Earnings Dispersion in the Sample}

Before drawing conclusions about the 1960-67 period, it is important to see whether earnings inequality based on data from the Pensionable Income Register (henceforth PIR) and the Income Register (henceforth IR) follow the same pattern over time. Figure 1 contains the P80-P20 ratio of earnings for my 1968-90 sample (based on the IR), where P80 is the 80 -th percentile of the earnings distribution. The figure also contains the P80-P20 ratio for 1960-88 based on earnings from the PIR with the same age interval as in my sample, which means that this series contains the P80-P20 ratio for my 1960-67 sample. The years 1989-90 of the PIR are excluded because more than 20 percent of the earnings are top-coded.

Figure 1 shows that the P80-P20 ratios based on earnings from the PIR and the IR follow the same general pattern over time. It is thus likely that they would display a similar pattern between 1960 and 1967 if data from IR were available for this period. ${ }^{15}$ The magnitude of inequality is, however, lower for earnings based on the PIR because fewer individuals with low earnings are present in this register; this may be explained by the requirement of being alive in 1990 and the requirement of not having any pension during a year. From 1980 onwards, earnings that form the basis for supplementary old-age pensions were also calculated for individuals with pension during a year. The effect of this is clearly seen in Figure 1 as the gap between the P80-P20 ratios decreases in 1980 .

Figure 1 also contains the variance of log annual earnings for my 1968-90 sample (based on the IR). The picture produced by the variance is very similar to

\footnotetext{
${ }^{15}$ The same is also true for the P50-P20 and P80-P50 ratios (available on request).
} 
that from the P80-P20 ratios. There are therefore strong reasons to believe that if earnings from the IR were available for 1960-67, the variance of log earnings for 1960-67 would display the same evolution as the P80-P20 ratio these years.

The second column of Table 2 shows that there is some variation in the age range in the sample, and this could affect the results in Figure 1. But a sample where the age interval each year is fixed at 26-53 produces almost identical results as in Figure 1. The main pattern is also the same for a sample aged 26-36 each year; the results in Figure 1 for 1960-67 are therefore not an artifact of sample selection. Hence, annual earnings dispersion was fairly constant between 1960 and 1968, decreased from the late 1960s to the mid 1970s, and increased after 1983.

Another study that investigates annual earnings inequality among men in Sweden between 1960 and 1967 is Spånt (1979). He also finds that inequality was fairly constant during these years. However, his results are not fully comparable as his measure of earnings also contains capital income and realization of capital gains.

Edin and Fredriksson (2000) use data from the IR in LINDA and report the standard deviation of log annual earnings for men between 1968 and 1990. They use the same earnings threshold as in this paper-the basic amount-but the definition of earnings differs slightly as they include sickness benefits after 1973 . The age interval also differs as each year they include men 20-64 years old. Nevertheless, their results are similar to those in Figure 1.

The pattern for 1968-90 produced by Figure 1 mimics the evolution of wage dispersion among men. Consistent with Figure 1, Edin and Holmlund (1995) report that wage dispersion rapidly decreased from the early to mid 1970s, was fairly constant until 1983, then slightly increased during the remainder of the period. Less is known about male wage dispersion between 1960 and 1967. Edin and Holmlund's (1995) paper contains the P75-P25 ratio of wages for white-collar male workers employed in the private sector between 1956 and 1990. The reported evolution of wage dispersion for this group mimics the pattern produced by Figure 1. To conclude, the evolution of earnings dispersion in my sample is very similar to what is known about Swedish wage dispersion.

\subsection{Remedial Measures for the 1960-67 Top-Coded Earnings}

The percentage of individuals with top-coded earnings steadily increases in the 1960-67 data (see the last column of Table 2). This will cause estimates of the variance to decrease over time. It will also affect changes in the auto-correlations of earnings, which identify changes in the ratio of persistent to transitory inequality. Unfortunately, there is no ideal way to adjust the top-coded earnings. For example, imputing the values by using some type of ordered probit would only capture the persistent part of earnings. Instead, I assume that earnings follow a log-normal distribution and, based on this distribution, approximate the topcoded observations with their conditional mean value; a related approach can be found in Hofer and Weber (2002). The estimation is done separately for each cohort and each year, that is, one set of parameters for the distribution is estimated for the cohort born in 1912/13 in 1960, and another set is estimated for this cohort in 1961, and so forth. 
In practice, the mean of log-earnings implied by the normal distribution for each cohort and year is estimated by standard maximum likelihood methods. The top-coded log-earnings are then adjusted to make the mean of all log-earnings for a given cohort and year equal to the mean implied by the normal distribution. For instance, the sample for the cohort born in 1912/13 in 1960 consists of 1,572 individuals. Of these, 106 individuals have top-coded earnings, with log earnings being equal to 12.37 (corresponding to 7.5 times the basic amount in real 1990 SEK). With these top-coded earnings included, the actual mean of log earnings for this cohort and year is 11.62, while the estimated true mean given that log earnings are normally distributed is 11.63. To get the actual mean being equal to the estimated mean, the values of the top-coded log earnings are adjusted upward from 12.37 to 12.56 , resulting in the actual mean being 11.63.

To evaluate how the use of the log-normal distribution and the "meanapproximation method" typically affect the variances and auto-covariances of log earnings, I have used the non-censored earnings for 1968-71 and artificially topcoded these to resample the top-coding present in the 1960-67 data. This simulation analysis shows that the resulting variances and auto-covariances are too low. Using the log log-normal distribution and the "mean-approximation method" on the artificially top-coded data results in variances and variances that are lower than those obtained from the corresponding correct data. ${ }^{16}$ However, and more important, the sign and the magnitude of the estimated changes over time resemble those of the correct data. ${ }^{17}$

As an alternative to the log-normal distribution I have also, as recommended by Cowell (2000), assumed that the upper tail of the earnings distribution for each cohort and year can be approximated by the Pareto distribution. This distribution did, however, not capture changes in variances and auto-covariances of earnings over time as well as the log-normal distribution - the most important aspect for the current application. ${ }^{18}$ Because of this, I choose to work with the log-normal distribution.

It is somewhat unexpected that the log-normal distribution outperforms the Pareto distribution for the upper part of the distribution; see, for instance Nirei and Souma (2007) for the opposite result. There are two potential explanations for this. First, I use a much narrower income measure - annual wages - than most previous studies that support the Pareto distribution. I also study a country with a very compressed wage structure. The upper tail of the distribution would probably be different for many other countries or if my earnings measure also consisted of capital income, as is the case in Nirei and Souma (2007). Second, in order to carry out the estimations, I am forced to assume that the highest 25 percent of earnings follows the Pareto, and this may be too high a number. Since the maximum share of top-coded earnings for a cohort and year is 16 percent, I have to make this assumption in order to ensure that enough non-censored earnings are included in the estimation of the parameters for each cohort and year specific Pareto distribution; see Gustavsson (2004) for further details on this. earnings.

${ }^{16}$ This implies that the log-normal distribution is unable to correctly capture the very highest

${ }^{17}$ The results are available in Gustavsson (2004).

${ }^{18}$ These results are available in Gustavsson (2004). 
Although the lognormal distribution quite correctly captures changes in inequality, the simulation with artificially top-coded data for 1968-71 indicates that resulting variances are too small. But even if this were not the case, the P80-P20 ratios in Figure 1 indicate that the variances in the period 1960-67 would be smaller than for later periods, since fewer individuals from the lower part of the earnings distribution are included during 1960-67. Hence, in order to be able to better compare inequality based on the 1960-67 data to later periods, it is necessary to re-scale the variances produced by the 1960-67 earnings.

Let $\operatorname{Var}\left(Y_{i b t}^{*}\right)$ denote the correct variance of log earnings for cohort $b$ in year $t$. Let $Y_{\text {ibt.norm }}$ be the log of earnings from the PIR for individuals in cohort $b$ where top-coded values have been approximated with their mean based on the lognormal distribution. Let $k_{b}$ be a constant that is used to re-scale all the values of $Y_{i b t, n o r m}$ for cohort $b$ so that the variances of $Y_{i b t}^{*}$ and $Y_{i b t, n o r m}$ are equal. This constant should then fulfill the equality

$$
\frac{\sum\left(k_{b} Y_{i b t, n o r m}-\left(\sum k_{b} Y_{i b t, n o r m}\right) / n\right)^{2}}{(n-1)}=\operatorname{Var}\left(Y_{i b t}^{*}\right),
$$

which can be written

$$
k_{b}=\sqrt{\frac{\operatorname{Var}\left(Y_{i b t}^{*}\right)}{\operatorname{Var}\left(Y_{i b t, n o r m}\right)}} .
$$

An estimate of $k_{b}$ in 1968 is obtained by estimating $\operatorname{Var}\left(Y_{i b t}^{*}\right)$ with the noncensored, representative earnings data from the IR for 1968 and by estimating $\operatorname{Var}\left(Y_{i b t, n o r m}\right)$ with data from the PIR for $1968 .{ }^{19}$ All earnings between 1960 and 1967 for cohort $b$ are then multiplied by their estimate of $k_{b}$. This cohort-specific procedure adjusts for the underestimation produced by the lognormal distribution but also recognizes that the non-representativeness of the data differs between cohorts. For example, the requirement of being alive in 1990 imposes more sample selection for the cohort born in 1912/13 than for the cohort born in 1940/41; consequently, older cohorts have higher estimates of $k_{b}$. Also, and of importance, the cohort specific auto-correlations, which identify the relative contribution from the persistent and transitory components, are unaffected by this re-scaling. This method of adjusting the 1960-67 earnings is further evaluated in Appendix B.

\section{Estimation Results}

Table 3 contains the estimated parameters and variances of the model outlined in equations (4)-(7); in total there are 131 parameters, all of which are precisely estimated and significantly different from zero. The first column of results refers to the persistent component and the second to the transitory component.

Starting with the persistent component, first are the age specific variances of the innovation in the random walk, denoted $\sigma_{u}^{2}, \sigma_{r, 28-29}^{2}, \sigma_{r, 30-31}^{2}$, and so forth, up

\footnotetext{
${ }^{19}$ The total share of earnings top-coded in the 1968 PIR is 12.97 percent.
} 
TABLE 3

Minimum Distance Estimates of Earnings Dynamics

\begin{tabular}{|c|c|c|}
\hline & Persistent Component & Transitory Component \\
\hline $\begin{array}{l}\text { Random walk va } \\
\sigma_{u}^{2} \\
\sigma_{r .28-29}^{2} \\
\sigma_{r .30-31}^{2} \\
\sigma_{r \cdot 32-33}^{2} \\
\sigma_{r .34-35}^{2} \\
\sigma_{r .36-37}^{2} \\
\sigma_{r .38-39}^{2} \\
\sigma_{r .40-41}^{2} \\
\sigma_{r .42-43}^{2} \\
\sigma_{r .44-45}^{2} \\
\sigma_{r .46-47}^{2} \\
\sigma_{r \cdot 48-49}^{2} \\
\sigma_{r .50-51}^{2} \\
\sigma_{r .52-53}^{2}\end{array}$ & $\begin{array}{l}0.0854(0.0036) \\
0.0167(0.0010) \\
0.0159(0.0010) \\
0.0157(0.0010) \\
0.0139(0.0010) \\
0.0131(0.0011) \\
0.0126(0.0011) \\
0.0138(0.0012) \\
0.0130(0.0012) \\
0.0121(0.0013) \\
0.0137(0.0014) \\
0.0128(0.0016) \\
0.0115(0.0018) \\
0.0105(0.0028)\end{array}$ & \\
\hline $\begin{array}{l}\text { ARMA-paramet } \\
\rho_{1960-67} \\
\delta_{1960-67} \\
\rho_{1968-90} \\
\delta_{1968-90}\end{array}$ & & $\begin{array}{r}0.8190(0.0209) \\
-0.5045(0.0235) \\
0.5726(0.0165) \\
-0.2579(0.0139)\end{array}$ \\
\hline $\begin{array}{l}\text { Parameters of th } \\
\gamma_{0} \\
\gamma_{1} \\
\gamma_{2}\end{array}$ & itory shocks & $\begin{array}{r}0.0526(0.0027) \\
-7.9 \mathrm{E}-4(2.4 \mathrm{E}-4) \\
3.4 \mathrm{E}-5(9.1 \mathrm{E}-6)\end{array}$ \\
\hline $\begin{array}{l}\text { Birth year } \\
1912 / 13 \\
1914 / 15 \\
1916 / 17 \\
1918 / 19 \\
1920 / 21 \\
1922 / 23 \\
1924 / 25 \\
1926 / 27 \\
1928 / 29 \\
1930 / 31 \\
1932 / 33 \\
1934 / 35 \\
1936 / 37 \\
1938 / 39 \\
1940 / 41 \\
1942 / 43 \\
1944 / 45 \\
1946 / 47 \\
1948 / 49 \\
1950 / 51 \\
1952 / 53 \\
1954 / 55 \\
1956 / 57 \\
1958 / 59\end{array}$ & $\begin{array}{c}q_{b} \\
0.7799(0.0247) \\
0.7941(0.0240) \\
0.8361(0.0242) \\
0.8827(0.0247) \\
0.8368(0.0225) \\
0.8657(0.0239) \\
0.9134(0.0237) \\
0.8873(0.0243) \\
0.9153(0.0246) \\
0.9667(0.0256) \\
1.0038(0.0265) \\
1.0000 \\
0.9931(0.0256) \\
1.0505(0.0271) \\
1.0494(0.0278) \\
1.0795(0.0271) \\
1.1076(0.0277) \\
1.1309(0.0304) \\
1.1146(0.0304) \\
1.1521(0.0334) \\
1.1869(0.0364) \\
1.2306(0.0381) \\
1.3249(0.0429) \\
1.3657(0.0466)\end{array}$ & $\begin{array}{c}\sigma_{b}^{2} \\
0.0548(0.0095) \\
0.0373(0.0088) \\
0.0572(0.0088) \\
0.0591(0.0104) \\
0.0544(0.0089) \\
0.0362(0.0098) \\
0.0670(0.0103) \\
0.0299(0.0095) \\
0.0620(0.0101) \\
0.0536(0.0096) \\
0.0442(0.0089) \\
0.0507(0.0077) \\
0.0683(0.0073) \\
0.0835(0.0068) \\
0.0854(0.0067) \\
0.0789(0.0063) \\
0.0973(0.0061) \\
0.0903(0.0059) \\
0.0956(0.0059) \\
0.0852(0.0060) \\
0.1047(0.0065) \\
0.0975(0.0061) \\
0.0965(0.0058) \\
0.0969(0.0059)\end{array}$ \\
\hline $\begin{array}{l}\text { Factor loadings } \\
1960 \\
1961\end{array}$ & $\begin{array}{l}p_{t} \\
1.0000 \\
0.9704(0.0063)\end{array}$ & 1.0000 \\
\hline
\end{tabular}

(C) 2008 The Author

Journal compilation (C) International Association for Research in Income and Wealth 2008 
TABLE 3 (continued)

\begin{tabular}{|c|c|c|}
\hline & Persistent Component & Transitory Component \\
\hline 1962 & $0.9533(0.0072)$ & 0.9847 (0.0219) \\
\hline 1963 & $0.9210(0.0077)$ & $1.0165(0.0246)$ \\
\hline 1964 & $0.8937(0.0081)$ & $1.0251(0.0253)$ \\
\hline 1965 & $0.8653(0.0083)$ & $1.0047(0.0258)$ \\
\hline 1966 & $0.8640(0.0088)$ & $1.0365(0.0263)$ \\
\hline 1967 & $0.8590(0.0093)$ & $1.0540(0.0270)$ \\
\hline 1968 & $0.8455(0.0093)$ & $1.0552(0.0248)$ \\
\hline 1969 & $0.8426(0.0099)$ & $1.0432(0.0259)$ \\
\hline 1970 & $0.8170(0.0103)$ & $1.0660(0.0261)$ \\
\hline 1971 & $0.8127(0.0109)$ & $1.1355(0.0278)$ \\
\hline 1972 & $0.7898(0.0111)$ & $1.0421(0.0252)$ \\
\hline 1973 & $0.7732(0.0113)$ & $1.0452(0.0248)$ \\
\hline 1974 & $0.7343(0.0114)$ & $1.0328(0.0243)$ \\
\hline 1975 & $0.7129(0.0115)$ & $1.0176(0.0240)$ \\
\hline 1976 & $0.7198(0.0122)$ & $1.0201(0.0238)$ \\
\hline 1977 & $0.7100(0.0125)$ & $1.0060(0.0241)$ \\
\hline 1978 & $0.6995(0.0130)$ & $1.0103(0.0247)$ \\
\hline 1979 & $0.6911(0.0133)$ & $0.9819(0.0243)$ \\
\hline 1980 & $0.6849(0.0137)$ & $1.0245(0.0255)$ \\
\hline 1981 & $0.6616(0.0138)$ & $1.0182(0.0256)$ \\
\hline 1982 & $0.6509(0.0141)$ & $1.0142(0.0261)$ \\
\hline 1983 & $0.6340(0.0142)$ & $0.9872(0.0261)$ \\
\hline 1984 & $0.6387(0.0147)$ & $1.0330(0.0271)$ \\
\hline 1985 & $0.6332(0.0148)$ & $0.9884(0.0266)$ \\
\hline 1986 & $0.6297(0.0150)$ & $1.0104(0.0271)$ \\
\hline 1987 & $0.6312(0.0155)$ & $1.0335(0.0285)$ \\
\hline 1988 & $0.6116(0.0154)$ & $1.0950(0.0285)$ \\
\hline 1989 & $0.6012(0.0155)$ & $1.0823(0.0282)$ \\
\hline 1990 & $0.5996(0.0158)$ & $1.1564(0.0290)$ \\
\hline
\end{tabular}

Note: The estimated model is outlined in equations (4)-(7). 4188 variances and covariances are used in the estimation, which in turn are based on 76,079 men and 1,144,667 individual-year observations. Robust standard errors are in parentheses.

to $\sigma_{r, 52-53}^{2}$. As the variance of a variable that follows a random walk is the sum of the variances of the innovation, the results imply that persistent inequality increases over the whole studied age-range. The innovation variances are largest at younger ages, something that is also found for the U.K. by Dickens (2000). This implies that persistent inequality rises with age at a diminishing rate (as was also discussed in Section 2). The presence of larger persistent shocks at younger ages is consistent with matching models in which information about a worker's ability is revealed over time, e.g. Jovanovic (1979).

Next in Table 3 are the cohort specific parameters $q_{b}$ in the persistent component. For identification, the value for the cohort born in 1934/35 is normalized to unity. ${ }^{20}$ The estimates are larger for younger cohorts. A natural first interpretation is that younger cohorts have more heterogeneous skills. Other interpretations of the $q_{b}$ estimates are possible though. It could be that younger cohorts consistently are hit by larger persistent shocks, even though they do not have a larger dispersion of skills. This could be the case if the labor market has become

${ }^{20}$ I have also estimated a specification where only the initial shock at age 27 is allowed to differ between cohorts. The number of estimated parameters in this specification is the same as in the specification in Table 3, but the sum of squared residuals is always larger. 
"tougher" over time. There has been a trend increase in Swedish youth unemployment (Edin and Holmlund, 1995), which does suggest that young individuals face a tougher labor market. Also, individuals included in the panel from older cohorts must have earnings above the basic amount in a later stage of life than younger cohorts. If individuals with lower skills drop out of the labor market over the life cycle, then the dispersion of skills in my sample will be higher for younger cohorts, even if this is not the case for the population as a whole. In the data, the sample size for a cohort generally decreases at older ages and those who drop out of the sample do generally have lower mean earnings. However, these effects mainly start around the age of 50. If sample selection were the sole explanation behind the results, one would not expect such large differences between cohorts who only are included in the sample while they are younger than 50 years.

Next in Table 3 are the estimated factor loadings on the persistent component, denoted $p_{t}$. For identification, the value for 1960 is normalized to unity. The factor loadings generally decrease during the whole sample period but the fall is more rapid up until the early 1980s than afterwards. Holding the cohort parameters constant, this implies a trend decrease in persistent inequality between 1960 and 1990.

Next I turn to the estimates for the transitory component. First are the parameters of the ARMA-process. Both the AR- and the MA-parameter are larger for 1960-67 than for 1968-90. This may be due to the data differences, but it may also be due to real labor market differences. The values $\hat{\rho}_{1960-67}=0.81$ and $\hat{\delta}_{1960-67}=-0.26$ imply that 55 percent of a transitory shock remains after 1 year, and that 22 percent remains after 5 years. The estimates for 1968 $90, \hat{\rho}_{1968-90}=0.57$ and $\hat{\delta}_{1968-90}=-0.26$, imply that 31 percent remains after 1 year, and that 3 percent remains after 5 years. The estimates for 1968-90 are of the same magnitude as the corresponding estimate for the U.S. reported in Haider (2001).

The parameters that allow for age heteroscedasticity in the variance of the transitory innovation follow next. The negative $\hat{\gamma}_{1}$ and the positive $\hat{\gamma}_{2}$ imply a U-shaped age profile similar to that reported for Canada in Baker and Solon (2003).

Next I turn to the estimated year-specific factor loadings on the innovation in the transitory process, denoted $\lambda_{t}$. Here, the factor loading for 1962 must be normalized to unity because the innovation variance in 1960 must be left unrestricted to identify the initial variances of the cohorts, i.e. the transitory variance in a cohort's first sample year is estimated solely by its initial variance. The estimates show that transitory shocks increased during the 1960s, steadily decreased from the early 1970 s to the early 1980 s, were fairly constant up to 1986 , and strongly increased thereafter.

Finally, the cohort specific initial transitory variances in Table 3, denoted $\sigma_{b}^{2}$, capture the accumulation of the transitory component up to the start of the sample period for each cohort. The estimates are all significantly larger than zero. Furthermore, Wald tests indicate that cohort differences in the initial variances are required.

What do the estimates in Table 3 imply about overall changes in the persistent and transitory variance of earnings? To study this I use the full model to predict the persistent and transitory components each year for individuals 40 years old. This 


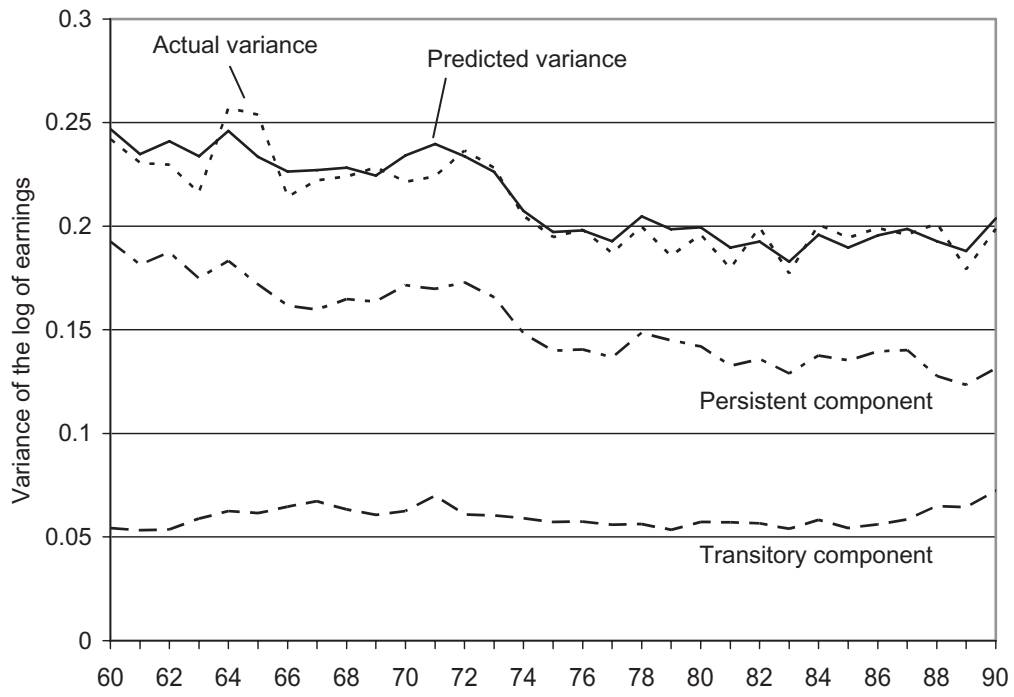

Figure 2. Decomposition of the Variance of Log Earnings Among 40-Year-Old Men

is the mid-point of the age range in the sample and should correspond to individuals in the middle of their working careers. Figure 2 displays the predictions. In moving from year to year the factor loadings on each component change, as do the

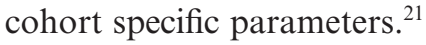

In Figure 2, the persistent component displays a downward trend during the whole sample period, but its decrease is much more rapid up until the early 1980s than afterwards. The transitory component steadily increases until the early 1970 s and then decreases to a similar magnitude in the early 1980s as in the early 1960s. From the mid 1980s onwards, it shows a clear upward trend.

Figure 2 also contains the predicted and actual variances for 40-year-olds. The predicted variance misses some year-to-year movements in the actual variance during the 1960s but captures the main pattern during the decade. After the 1960s, the predicted variance quite closely captures the movements in the actual variance.

I have also performed decompositions for 30- and 50-year-olds (available on request). Changes during the 1960s and the 1970s are similar to those for 40 -yearolds, but some differences stand out during the 1980s. For 30-year-olds, both the persistent component and the predicted/actual variance increase noticeably after 1983. For 50-year-olds, the persistent component is constant during the second half of the 1980s, and as a result, the predicted/actual variance increases slightly. Hence, the fact that the overall variance in Figure 2 does not go up in the last part of the 1980s, as would be expected from Figure 1, is a result specific to 40-year-olds; for both 30 - and 50 -year-olds, the overall variance instead increases during this period.

The increase in the transitory variance of earnings during the second half of the 1980s has an interesting link to wages. According to Edin and Holmlund

${ }^{21}$ In fact, the cohort specific parameters change every two years. For example, in 1960/61 the cohort specific estimates for the cohort born in 1920/21 are used as members of this two-year birth cohort are 40 years old at this time. For 1962/63, the estimates for the cohort born in 1922/23 are used. 
(1995), a majority of the increase in wage dispersion during the second half of the 1980s was driven by increased within-group dispersion. This could be due to increased returns to (for the econometrician) unobserved skills, but it could also be due to increased wage instability. The results in this paper support the latter explanation.

To test the robustness of the above results, I have carried out four main sensitivity analyses (all results are available in Gustavsson, 2004). First, I have looked at whether the results change when separate estimations are performed for the 1960-67 and 1968-90 periods. Second, I have performed estimations based on the balanced revolving panel design employed in Haider (2001) and Baker and Solon (2003). Third and fourth, I have tested how the estimates change when a lower earnings threshold and an earnings threshold adjusted for changes in real wages are used in the sample construction. None of these analyses do however question the results presented in Figure 2.

\section{A Cross-National Comparison}

Are the changes in persistent and transitory inequality in Sweden unique, or are they part of a common international pattern? To put the estimates in this paper into perspective, this section compares the findings for Sweden to what is known for other countries between 1960 and 1990. However, due to the need of rich longitudinal data, studies are (as far as I know) available only for the U.S., Canada, the U.K., and Italy. In addition, information for the whole of the 1970s and 1980s is available only for the U.S. Because of this, the U.S. results will constitute the main benchmark.

It is also important to remember that different kinds of data sources and different sample designs are used across studies which undoubtedly will influence the estimated size of the persistent and transitory components. However, it is far from obvious that it should have a large effect on the estimated changes over time, but the possibility of this should of course be kept in mind when discussing the results.

Figure 3A displays the evolution of the persistent variance of log earnings in the U.S. between 1967 and 1990 for white males based on the results in Haider (2001) along with similar estimates for Sweden between 1960 and 1990 based on the results in Table $3 .^{22}$ The value for 1967 is normalized to unity in both series.

Compared to Sweden, U.S. persistent inequality is much more constant during the 1970s. In the 1980s, however, there is a rapid increase in the U.S. whereas Sweden experiences a slight decrease. These patterns correspond well to what is known about the U.S.-Sweden differences in the evolution of the returns to skills, for example the return to education (e.g. Freeman and Katz, 1995).

Dickens (2000) contains results for the U.K. between 1975 and 1995, and Baker and Solon (2003) present results for Canada between 1976 and 1992. In both these countries, persistent inequality increased markedly during the 1980s, though the increase in Canada appears to have been smaller than that in the U.S. and the

\footnotetext{
${ }^{22}$ Moffitt and Gottschalk (2002) report results for the U.S. similar to those in Haider (2001). I am, however, not able to graph these as they do not report their parameter estimates.
} 
(A) Persistent Variance

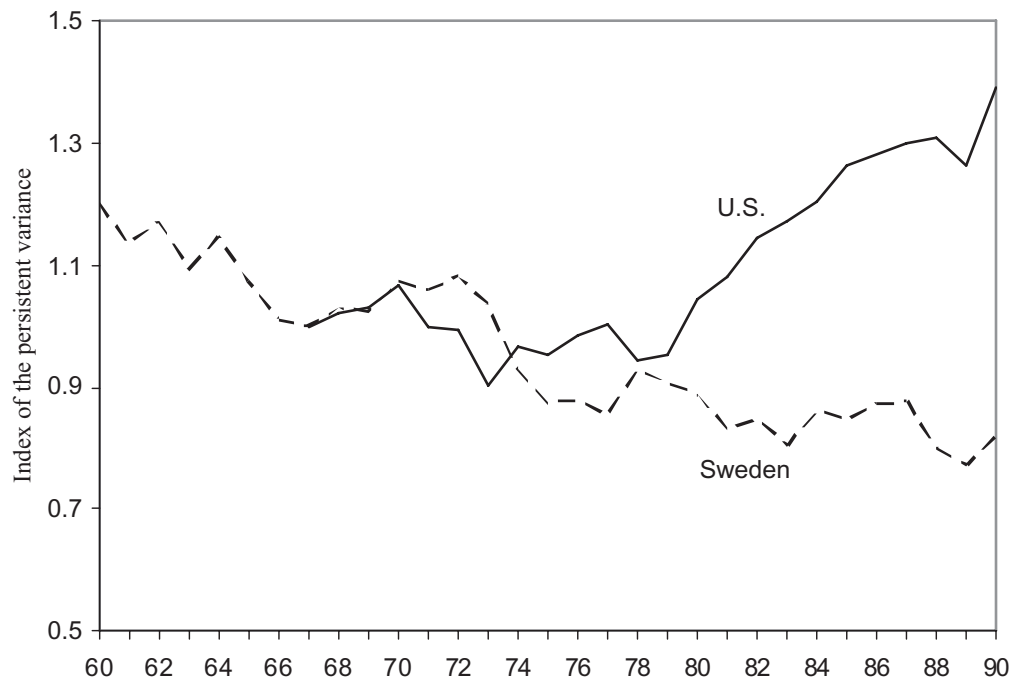

(B) Transitory Variance

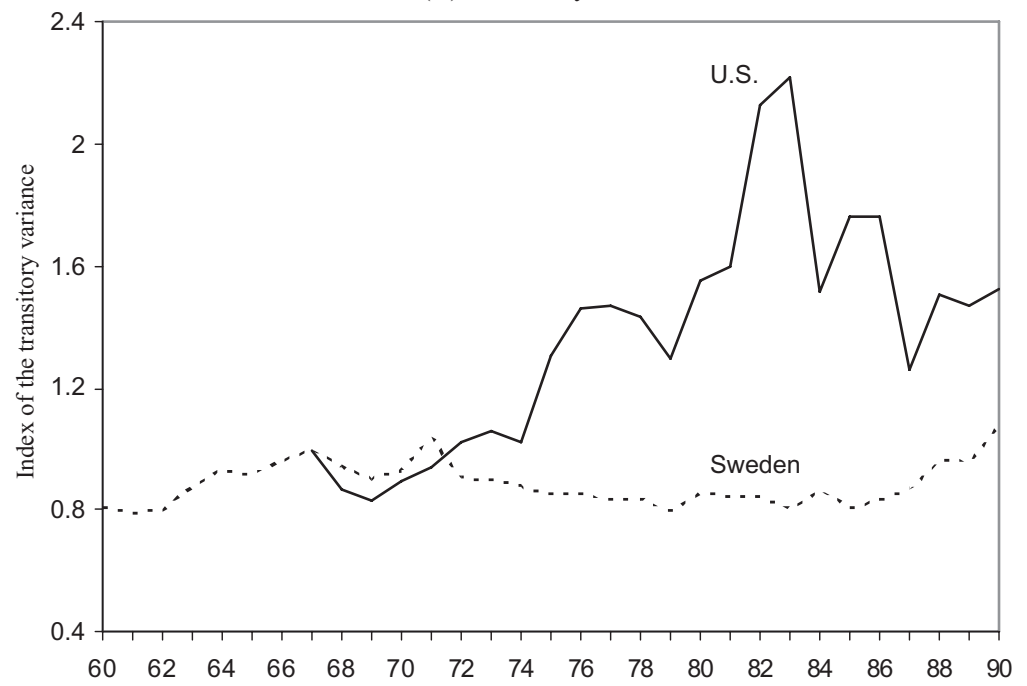

Figure 3. The Evolution of the Persistent (A) and Transitory (B) Variance of Log Earnings in the U.S. Between 1967 and 1990 and in Sweden Between 1960 and 1990

Note: The value for 1967 is normalized to unity in both series. The numbers for Sweden are for 40 -year-olds and cohort heterogeneity is included in the predictions. Haider (2001) does not allow for cohort heterogeneity in the persistent and transitory components of earnings or for age variation in the transitory component of earnings.

Source: The numbers for the U.S. are based on Haider (2001), Table 5, columns 2 and 4. The numbers for Sweden are based on Table 2.

U.K. In contrast, Cappellari (2004) contains results for Italy between 1979 and 1995 which indicate that the persistent variance of earnings declined during the 1980s, with the magnitude of the decrease similar to that in Sweden. 
In the same manner as for the persistent variance, Figure 3B displays the evolution of the transitory variance of log earnings in the U.S. between 1967 and 1990 based on Haider (2001), along with corresponding estimates for Sweden between 1960 and 1990. The difference between Sweden and the U.S. during the 1970 s is striking. According to Haider's estimates, U.S. earnings instability strongly increased from the beginning of the 1970s to the early 1980s, and the increase was clearly much stronger than anything experienced in Sweden between 1960 and $1990 .^{23}$ The experiences of the two countries also diverged markedly during the second half of the 1980s as instability decreased in the U.S. but increased in Sweden.

The results in Dickens (2000) and Baker and Solon (2003) indicate that earnings instability in Canada and the U.K. increased noticeably during the first half of the 1980s, though the increases do not appear to have been as powerful as that in the U.S. The results in Cappellari (2004), on the other hand, indicate that the transitory variance of earnings decreased in Italy during the 1980s.

Overall, there are some interesting cross-national patterns in how persistent and transitory inequality have evolved during the 1980s. The U.S., the U.K., and to some extent Canada, have experienced similar changes in both persistent and transitory inequality. Sweden and Italy appear to share a similar pattern in terms of persistent inequality but to differ in how transitory inequality has evolved.

\section{Concluding Remarks}

Using a large individual longitudinal database, this paper decomposes the cross-sectional variance of male annual earnings in Sweden between 1960 and 1990 into its persistent and transitory components. The persistent variance displays a downward trend during the whole sample period, but with the rate of decline more rapid up until the early 1980s than afterwards. The transitory variance increased from 1960 until the early 1970s, decreased slightly until the late 1970s, and then rose again during the second half of the 1980s.

That persistent inequality decreased at a rapid pace in Sweden from 1968 to the mid 1970s is well known - at least as captured by standard Mincerian wage equations - but exactly what happened before 1968 has long been unknown. Since the strongly egalitarian version of the solidarity wage policy was brought into practice in the late 1960s, this lack of knowledge has resulted in a blurry picture of how the implementation of this policy co-varied with changes in inequality. The results in this paper have provided additional light on this question. In particular, the results show that 1968 was not the year when compression of persistent earnings in Sweden took off; it was simply part of a trend that had begun at least

\footnotetext{
${ }^{23}$ Of course, part of this can be due to a much lower earnings threshold in Haider (2001), but the estimates that I have performed with a lower threshold did not predict more powerful trends in the transitory variance; see Gustavsson (2004). Based on the results in Haider (2001), I have estimated a time-series regression of the transitory component (normalized to unity in 1967) on a constant, a linear time trend, and the unemployment rate. A one-percentage point increase in the unemployment rate is significantly associated with a 0.14 increase in the normalized transitory component. Part of the higher earnings instability in the U.S. in the first half of the 1980s compared to the early 1970 s is therefore likely to be due to a higher unemployment rate, but this can only explain part of the strong increase.
} 
as early as 1960 . This could be an indication that the solidarity wage policy had a smaller role in the compression of wages in Sweden than is commonly believed.

Another important lesson from the results in this paper concerns the interpretation of the rise in cross-sectional inequality observed after the 1983 breakdown of centralized bargaining in Sweden. For example, Edin and Topel (1997) argue that human capital investments in Sweden were discouraged by the union driven wage compression, and adduce the resulting scarcity of skilled labor as a main explanation for the end of centralized bargaining. With this story, one would expect the shift in wage bargaining to be accompanied by increased dispersion in persistent earnings, since earnings differentials between low and high skilled workers should increase systematically. At first glance, this also appears to be the case as cross-sectional inequality actually began to increase in the mid 1980s. However, the results in this study show that this rise was in fact due to increased dispersion in transitory earnings, hence casting doubt on Edin and Topel's story.

A comparison of the evolution of persistent and transitory inequality in Sweden with evidence for the U.S. reveals sharp differences. In particular, this paper indicates a large and previous unknown difference between the U.S. and Sweden in terms of the evolution of earnings instability. In the U.S., unlike in Sweden, earnings instability increased noticeably from the mid 1970s to the mid 1980s, and the change appears to be much stronger than anything experienced in Sweden between 1960 and 1990. Future studies that examine in more detail crosscountry differences in the evolution of persistent and transitory earning inequality are therefore warranted.

\section{Appendix A: The Estimation Procedure}

The parameters of the model in equations (4)-(7) are estimated by applying the minimum distance estimator of Chamberlain (1984). I first estimate $\mu_{b t}$ in equation (1) with the sample mean log of earnings for the birth cohort $b$ in year $t$. Deviation of observed log earnings $Y_{i b t}$ from that mean is then treated as a measure of $y_{i b t}$, i.e. current relative earnings. This simple procedure adjusts for age, year, and cohort effects on average earnings.

For each of the 24 sample cohorts, born in 1912/13 through 1958/59, I construct the sample auto-covariance matrix of $y_{i b t}$. For the two cohorts observed for the whole 27-53 age-span, born in 1932/33 and 1934/35, these are $27 \times 27$ matrices; the matrices for other cohorts have a smaller dimension. The distinct elements of each cohort's auto-covariance matrix are listed in a vector $\hat{\mathbf{C}}_{b}$, which contain $378=(27 \times 28) / 2$ elements for the two cohorts observed for the whole 27-53 age-span and fewer elements for the other cohorts. The $\hat{\mathbf{C}}_{b}$ vectors are stacked into an aggregate vector $\hat{\mathbf{C}}$, which contains a total of 4,188 distinct autocovariance elements.

Let $\mathbf{C}$ be the population analog to $\hat{\mathbf{C}}$. Express my model's moment restrictions as $\mathbf{C}=f(\boldsymbol{\theta})$, where $\boldsymbol{\theta}$ is a vector that contains all the parameters of my model. The model in equations (4)-(7) then implies that the general variance element in $\mathbf{C}$ is 


$$
\begin{aligned}
\operatorname{Var}\left(y_{i b t}\right)= & p_{t}^{2} q_{c}^{2}\left(\sigma_{u}^{2}+\sum_{a} \sigma_{r a}^{2}\right)+\rho_{t}^{2} \operatorname{Var}\left(\varepsilon_{i b, t-1}\right) \\
& +\left(2 \rho_{t} \delta_{t}+\delta_{t}^{2}\right) \lambda_{t-1}^{2}\left(\gamma_{0}+\gamma_{1}(a-1)+\gamma_{2}(a-1)^{2}\right)+\lambda_{t}^{2}\left(\gamma_{0}+\gamma_{1} a+\gamma_{2} a^{2}\right),
\end{aligned}
$$

and that the general auto-covariance element for $y_{i b t}$ and $y_{i b, t-1}$ is

$$
\begin{aligned}
\operatorname{Cov}\left(y_{i b t}, y_{i b, t-1}\right)= & p_{t} p_{t-1} q_{c}^{2}\left(\sigma_{u}^{2}+\sum_{a-1} \sigma_{r a}^{2}\right)+\rho_{t} \operatorname{Var}\left(\varepsilon_{i b, t-1}\right) \\
& +\delta_{t} \lambda_{t-1}^{2}\left(\gamma_{0}+\gamma_{1}(a-1)+\gamma_{2}(a-1)^{2}\right),
\end{aligned}
$$

and that the general auto-covariance element for $y_{i b t}$ and $y_{i b, t-s}$, where $s>1$, is

$$
\begin{aligned}
\operatorname{Cov}\left(y_{i b t}, y_{i b, t-s}\right)= & p_{t} p_{t-s} q_{c}^{2}\left(\sigma_{u}^{2}+\sum_{a-s} \sigma_{r a}^{2}\right)+\left(\prod_{t-s+1}^{t} \rho_{t}\right) \operatorname{Var}\left(\varepsilon_{i b, t-s}\right) \\
& +\left(\prod_{t-s+2}^{t} \rho_{t}\right) \delta_{t-s+1} \lambda_{t-s}^{2}\left(\gamma_{0}+\gamma_{1}(a-s)+\gamma_{2}(a-s)^{2}\right) .
\end{aligned}
$$

In equations (A1)-(A3), $\rho_{t}$ and $\delta_{t}$ are allowed to differ between, but not within, the periods $1960-67$ and $1968-90$.

With $\mathbf{C}=f(\boldsymbol{\theta})$ specified, the vector $\hat{\boldsymbol{\theta}}$ is chosen to minimize a distance function

$$
\mathbf{D}=(\hat{\mathbf{C}}-f(\hat{\boldsymbol{\theta}}))^{\prime} \mathbf{W}(\hat{\mathbf{C}}-f(\hat{\boldsymbol{\theta}})),
$$

where $\mathbf{W}$ is a positive definite weighting matrix. The asymptotically optimal choice of $\mathbf{W}$ is the inverse of any consistent estimator of the covariance matrix of $\mathbf{C}$. However, Altonji and Segal (1996) and Clark (1996) provide Monte Carlo evidence of potential serious finite sample bias in the estimate of $\boldsymbol{\theta}$ with this approach. I therefore follow the practice of the most recent literature and use the identity matrix as the weighting matrix. This "equally weighted minimum distance estimation" amounts to using non-linear least squares to fit $f(\hat{\boldsymbol{\theta}})$ to $\hat{\mathbf{C}}$. As outlined in Chamberlain (1984), robust standard errors for $\hat{\boldsymbol{\theta}}$ are obtained from the formula

$$
\left(\mathbf{G}^{\prime} \mathbf{G}\right)^{-1} \mathbf{G}^{\prime} \mathbf{V G}\left(\mathbf{G}^{\prime} \mathbf{G}\right)^{-1}
$$

where $\mathbf{G}$ is the gradient matrix $\partial f(\boldsymbol{\theta}) / \partial \boldsymbol{\theta}$ evaluated at $\hat{\boldsymbol{\theta}}$ and $\mathbf{V}$ is a block diagonal matrix containing the estimated covariance matrices of each $\hat{\mathbf{C}}_{b}$ vectors.

\section{APPENDix B: Estimates FOR 1968-90 with TOP-CODED 1968-75 EARNINGS}

The results in Figure 2 in the main text indicate that the persistent component decreased between 1960 and 1967 while the transitory component instead increased. Could this result be an artifact from the continuous increase in the share of top-coded earnings? Or is it in some way due to sample selection? To further investigate how the top-coded observations, sample selection, and the meanapproximation influence the results for the 1960-67 period, I have adjusted the accurate 1968-76 earnings data so as to replicate the top-coded 1960-68 data. Note that in the original analysis, top-coded data for 1968 are used to estimate the scale parameters $k_{b}$ (see Section 3.3), and artificially top-coded data for 1976 hence corresponds to top-coded data for 1968. 


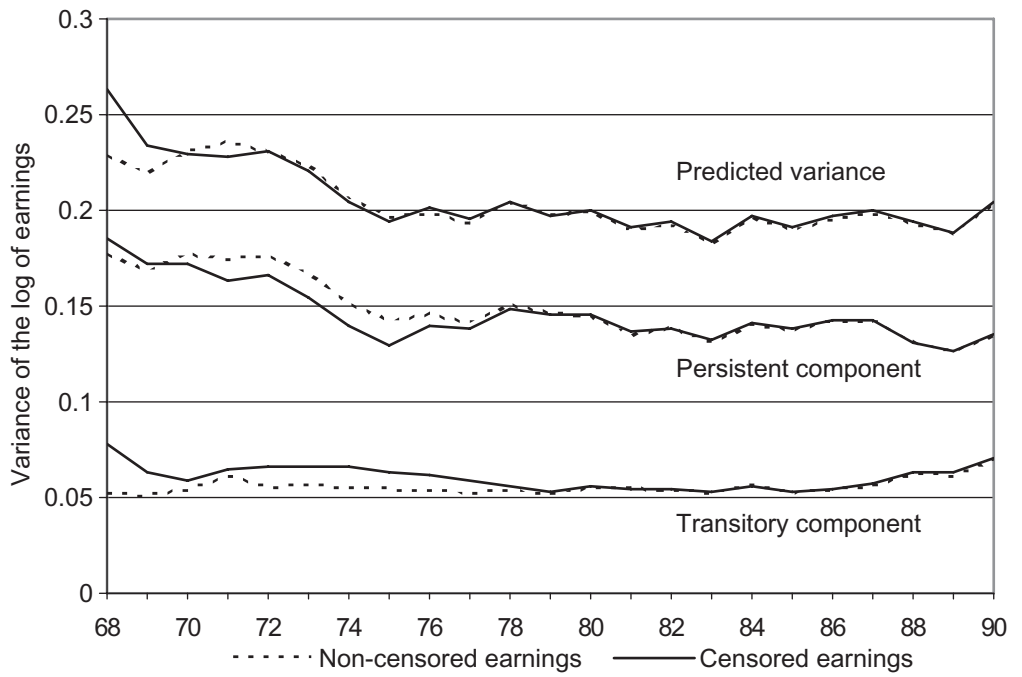

Figure A1. Decomposition of the Variance of the Log of Earnings among 40-Year-Old Men, based on 1968-90 Panels where One Panel Contains Accurate Earnings and the Other Contains Mean-Approximated Top-Coded Earnings 1968-75

The data have been adjusted as follows. First, only individuals included in the PIR between 1968 and 1976 are selected. This imposes sample selection as they cannot have pensions and must still be alive and living in Sweden in 1990although the selection is smaller than during 1960-68. Second, their recorded earnings from the IR during 1968-76 are artificially top-coded to match the top-coded 1960-68 earnings. That is, Table 1 shows that in 1960 the percentage top-coded is 4.65 , the cut-off point for 1968 is then set so that the percentage top-coded this year is 4.65. The percentage top-coded earnings in 1961 is 5.51, so the 1969 earnings data are transformed to having 5.51 percentage top-coded observations, and so forth until 1976 which corresponds to 1968 in the 1960-90 analysis (the share top-coded in 1968 is 12.96 percent). The top-coded values for the 1968-75 period are then approximated by their estimated mean values based on the lognormal distribution for each cohort and year in the same manner as for the 1960-67 data. To estimate the scale constant $k_{b}$ I use the top-coded observations with sample selection for 1976 and the accurate earnings without sample selection for the same year. This corresponds to the use of the 1968 data for the estimate of the scale constant for the 1960-67 earnings. Based on the meanapproximated top-coded 1968-75 earnings and accurate 1976-90 earnings, I estimate the model in equations (4)-(7) for the years 1968-90. Figure A1 contains the two predicted components for 40-year-olds. As a benchmark, results based on a 1968-90 panel with correct earnings data are also included in Figure A1.

The mean-approximated data correctly capture the main pattern of the persistent component. For the transitory component, the mean-approximated data lead to constant estimates during some of the years when the estimates based on accurate data instead decrease slightly; hence, there seems to be a slight effect from the year-to-year increase in the percentage of earnings that are top-coded. 
However, despite some wrong year-to-year movements for the transitory component, the estimates correctly capture the decrease during the 1970s as a whole.

For inference concerning the 1960-67 period, it should also be observed that the transitory component in Figure A1 is overestimated and that the overestimation is larger in the first two years. The persistent component is underestimated, except in the first two years when it is overestimated. These results indicate that the estimated scale parameters, $k_{b}$, are too large for the first sample years and that this causes the estimates of both components to be too large in these years. It is likely that this also applies to the results for the 1960-67 period. The estimated increase in the transitory component between 1960 and 1967 might thus actually be too small, as the transitory component is likely to be more overestimated in the beginning of the 1960s. In the same manner, the estimated decrease in the persistent component might be too large.

\section{REFERENCES}

Altonji, J. and L. Segal, "Small-Sample Bias in GMM Estimation of Covariance Structures," Journal of Business and Economic Statistics, 14, 353-66, 1996.

Baker, M., "Growth Rate Heterogeneity and the Covariance Structure of Life-Cycle Earnings," Journal of Labor Economics, 15, 537-79, 1997.

Baker, M. and G. Solon, "Earnings Dynamics and Inequality among Canadian Men, 1976-1992: Evidence from Longitudinal Tax Records," Journal of Labor Economics, 21, 289-321, 2003.

Björklund, A., "A Comparison Between Actual Distribution of Annual and Lifetime Income: Sweden 1951-89," Review of Income and Wealth, 39, 377-86, 1993.

Cahuc, P. and A. Zylberberg, Labor Economics, The MIT Press, Cambridge, 2004.

Cappellari, L., "The Dynamics and Inequality of Italian Men's Earnings: Long-term Changes or Transitory Fluctuations?" Journal of Human Resources, 39, 475-99, 2004.

Chamberlain, G., "Panel Data," in Z. Griliches and M. Intriligator (eds), Handbook of Econometrics, Vol. 2, Elsevier Science, Amsterdam, 1984.

Clark, T., "Small-Sample Properties of Estimators of Nonlinear Models of Covariance Structure," Journal of Business and Economic Statistics, 14, 367-73, 1996.

Cowell, F., "Measurement of Inequality," in A. Atkinson and F. Bourguignon (eds), Handbook of Income Distribution, Vol. 1, Elsevier Science, Amsterdam, 2000.

Dickens, R., "The Evolution of Individual Male Earnings in Great Britain: 1975-95," Economic Journal, 110, 27-49, 2000.

Edin, P-A. and P. Fredriksson, "LINDA_-Longitudinal Individual Data for Sweden," Working Paper 2000:19, Department of Economics, Uppsala University, 2000.

Edin, P-A. and B. Holmlund, "The Swedish Wage Structure: The Rise and Fall of Solidarity Wage Policy?" in R. Freeman and L. Katz (eds), Differences and Changes in Wage Structures, University of Chicago Press, Chicago, 1995.

Edin, P-A. and R. Topel, "Wage Policy and Restructuring: The Swedish Labor Market Since 1960," in R. Freeman, R. Topel, and B. Swedenborg (eds), The Welfare State in Transition, University of Chicago Press, Chicago, 1997.

Freeman, R. and L. Katz, Differences and Changes in Wage Structures, University of Chicago Press, Chicago, 1995.

Gottschalk, P. and R. Moffitt, "The Growth of Earnings Instability in the U.S. Labor Market," Brookings Papers on Economic Activity, 25, 217-72, 1994.

Gustafsson, B., "The Degree and Pattern of Income Immobility in Sweden," Review of Income and Wealth, 40, 67-86, 1994.

Gustavsson, M., "Trends in the Transitory Variance of Earnings: Evidence from Sweden 1960-1990 and a Comparison with the United States," Working Paper 2004:11, Department of Economics, Uppsala University, 2004.

,"The 1990s Rise in Swedish Earnings Inequality: Persistent or Transitory?" Applied Economics, 39, 25-30, 2007.

Haider, S., "Earnings Instability and Earnings Inequality of Males in the United States: 1967-1991," Journal of Labor Economics, 19, 799-836, 2001.

Hamilton, J., Time Series Analysis, Princeton University Press, Princeton, 1994. 
Hibbs, D., "Wage Dispersion and Trade Union Action in Sweden," in I. Persson (ed.), Generating Equality in the Welfare State-The Swedish Experience, Norwegian University Press, Oslo, 1990.

Hibbs, D. and H. Locking, "Wage Dispersion and Productive Efficiency: Evidence for Sweden," Journal of Labor Economics, 18, 755-82, 2000.

Hofer, H. and A. Weber, "Wage Mobility in Austria 1986-1996," Labour Economics, 9, 563-77, 2002.

Jovanovic, B., "Job Matching and the Theory of Turnover," Journal of Political Economy, 87, 972-90, 1979.

Katz, L. and D. Autor, "Changes in the Wage Structure and Earnings Inequality," in O. Ashenfelter and D. Card (eds), Handbook of Labor Economics, Vol. 3A, Elsevier Science, Amsterdam, 1999.

Leamer, E., "Let's Take the Con Out of Econometrics," American Economic Review, 75, 31-43, 1983.

MaCurdy, T., "The Use of Time Series Processes to Model the Error Structure of Earnings in Longitudinal Data Analysis," Journal of Econometrics, 18, 83-114, 1982.

Moffitt, R. and P. Gottschalk, "Trends in the Transitory Variance of Earnings in the United States," Economic Journal, 112, 68-73, 2002.

Newey, W., "Generalized Method of Moments Specification Testing," Journal of Econometrics, 29, 229-56, 1985.

Nirei, M. and W. Souma, "A Two Factor Model of Income Distribution Dynamics," Review of Income and Wealth, 53, 440-59, 2007.

Palme, M., "Earnings Mobility and Distribution: Comparing Statistical Models on Swedish Data," Labour Economics, 2, 213-47, 1995.

Ramos, X., "The Covariance Structure of Earnings in Great Britain, 1991-1999," Economica, 70, $353-74,2003$.

Riksförsäkringsverket, “Intjänad pensionspoäng inom ATP 1960-1982,” Statistisk rapport 1984:7, Riksförsäkringsverket, 1984.

Spånt, R., "Den svenska inkomstfördelningens utveckling 1920-1976," background material to Långtidsutredningen 1978, Ds E 1979:4, 1979. 